\title{
REVIEW
}

\section{Olympic Economics}

\section{Holger Preuss, The Economics of Staging the Olympics: A comparison of the Games 1972-2008, Edward Elgar, Cheltenham, 2004}

\section{Reviewed by Ray Trewin}

$\mathrm{T}$ The author is an economist at Germany's Johannes Gutenberg University, and a member of its Research Team Olympia. This book adds to his extensive list of publications on the Olympics. The dust cover states that 'academics and researchers of sports economics, international economics, international business and competition will all find this fascinating book of great value', and that 'it will also appeal to those interested in the broader context of the Olympic Games and concerned by their commercialization and gigantism'.

Some of the big economic issues covered in this book include: costs versus benefits to the host city (usually jointly liable with the associated Organising Committee of the Olympic Games (OCOG), for debt incurred); the appropriate public and private sectors financing mix; and the increasing economic scale of what is basically a two-week event held every four years. It is disappointing that there is no similar consideration of the political economy of the Games, which might help explain the choice of a particular host city when purely technical considerations suggest that another might be more appropriate. By contrast, Simson and Jennings (1992) present a number of examples, such as excessive gift giving (now curtailed - presumably because of its obvious potential influence on the bidding process); Barcelona strategists splitting support for the Paris bid in 2005 by backing Albertville for the winter Olympics; and technical evaluations by an IOC committee being watered down before presentation).

Although the author makes a number of strong points, several other more debatable views are also advanced. In the introductory chapter, for example, a number of benefits attributed to the Olympics (such as better health through encouraging active participation in sporting activity, increased tourism, and increased trade) would seem to be of minor significance.

Chapter 2 describes the transformations of money values necessary for financial comparisons of various Olympics used in Chapter 3 to identify the shift in financing from the public sector to privately owned corporations. The mix ranges from mainly public (Montreal in 1976) to mainly private (Los Angeles in 1984). This change seems to be related to commercialisation of the Games, and a trend to more efficient private sector involvement in infrastructure development.

Chapter 4 deals with the expanding size of investment in the Games. An example of its consequences is that the debt incurred to run the 1976 Games is still 
being repaid by Montreal citizens three decades later. More recent Olympiads have witnessed some constraint on this growth, such as concerns about the ecological impact of constructing large sports facilities. The author proposes a limited solution by way of relying on temporary facilities (for example, extra seating in the Sydney Olympic stadium; a plastic pool in an exhibition hall at the 2001 swimming world championships; and a velodrome in Atlanta).

Chapter 5 outlines methods for analysing the economic impact of the Games. Cost-benefit analysis (from the host city's perspective) is proposed as the ideal approach. The similarity of revenues and expenditures suggests the importance of intangibles in the conclusions. The author argues that cost-benefit analysis is not possible, however, because of a lack of uniform financial data, so a more limited input-output analysis is attempted. This is restricted to just the tangible aspects; intangible effects and indirect impacts are not considered. Nevertheless, several rules that should be built into any attempt at cost-benefit analysis are listed:

- $\quad$ only additional net spending by tourists can provide a benefit, as distinct from redirected spending by local citizens;

- $\quad$ some Olympic expenditures can crowd out other activities, so the associated costs of transferred resources need to be accounted for;

- whether there is a boom or bust when planned Olympic investment is actually undertaken is important in determining the ultimate crowding out effect;

- inflation that results from the Olympics causing aggregate demand to exceed supply can reduce the overall benefits; and

- the use of a wide range of multipliers (from 1.5 to 3 in pre- and post evaluations of the Los Angeles Games, for example) to estimate secondary impacts is inappropriate.

A more appropriate approach than that set out in Chapter 5 might have been an institutional analysis that sought to explain seemingly irrational economic behaviour where intangibles override the basic economics. Examples include the continuation - despite low public interest and limited participation - of the modern pentathlon (which usually requires new facilities and heavy expenditures such as those associated with caring for horses); the foregoing of higher revenues from cable television in favour of more accessible free-to-air television; and the poorly attended cultural program run in conjunction with the sporting events. (The cultural program cost US\$71 million in Barcelona, but only returned US\$29 million in revenue.) There is some attempt to explain such aspects (with references to maintaining tradition, status seeking, and the attempt to build public support), but this is not presented in a consistent framework or in a focused manner.

In Chapter 6 the author looks, sometimes uncritically, at the alleged benefits to the host community in terms of increased tourism, exports and foreign investment. For example, he mentions post-Sydney Games research by PricewaterhouseCoopers on leveraging off the Olympics, which included a contribution of US\$217 million in new sales and investment purportedly generated by an 'Australian Technology Showcase', whereas other research showed no 
change in Australia's attractiveness as a destination for investment as a result of the Games. He does include some reality checks, however. For example, he notes that the Australian Bureau of Statistics reported only 53,000 extra visitors to Australia - compared with the typical number of around 400,000 - over the month of the Sydney Olympics, which was much less than predicted. The chapter also contains a useful discussion (from the host city perspective) of negative impacts on tourism generated by the Games, such as city residents and potential visitors taking holidays elsewhere in order to avoid Olympic disruptions.

Chapter 7 discusses infrastructure investment, emphasising the importance of planning for the post-Olympics utilisation of the infrastructure, to avoid creating facilities that will become white elephants after the Games are over. Although this point should be obvious, it has been ignored by many host cities in their enthusiasm to make a strong impression and thus ensure the success of their bid.

Chapter 8 focuses on revenues. This is the longest chapter, perhaps reflecting the key concern of the IOC - also apparent in the transformation of the Committee for the Protection of the Olympic Symbol to become the New Sources of Financing Committee, under former IOC president Samaranch. The chapter outlines the expansion of IOC powers over host cities and OCOGs, and discusses some countervailing forces. For example, 'over-commercialisation' of the Games is held back by public disquiet (especially outside the US) about overly prominent advertising and merchandising, as in Atlanta: over 50 per cent and up to 76 per cent of spectators interviewed after recent Games thought commercialisation was a threat to their future. The IOC has reacted to this by banning advertising and merchandising at Olympic sites, as well as advertising on athletes' clothing and equipment. Other 'over-commercialisation' aspects of concern include the disappearance of amateurism as a result of increasingly large rewards to athletes, which also encourages the use of drugs by some to gain an unfair advantage.

Since 1985 the IOC has limited the number of principal Olympics sponsors (those granted worldwide exclusive rights, within set categories, to incorporate Olympic symbols in advertising), thus increasing its revenues significantly. An interesting constraint to this power is also discussed: 'ambush marketers' who associate themselves with the Olympics - say, through sponsorship of wellknown athletes - but pay no marketing fees to the Olympic movement.

The anticipated revenues for the 2008 Beijing Olympics presented in this chapter appear to be gross underestimates, reversing the increasing trend evident since Montreal in 1976, as do the anticipated expenditures presented in Chapter 9. It would be interesting to know if these numbers were deliberately underestimated in order to maximise the chances of achieving a successful bid, given a perceived desire for smaller Games. It is hard to imagine that spectators close to the Olympic village will really ride bicycles to the venues, as was stated in the bid.

Chapter 10 discusses the employment impact of the Games, making the important point that new employment generated is just a different way of looking at the boost to economic activity, not an additional benefit. Chapter 11, on the aftermath of the Olympics, deals mainly with concerns about price increases. In the case of the 2000 Olympics the author found no significant price differences 
between Sydney and other Australian cities, but this seems a poor test of the Olympics' impact on prices, as he states elsewhere that the crowding out effect would have a broad Australia-wide impact.

Chapter 12 draws some conclusions, one of which is a recommendation for a uniform accounting approach across all Olympics so that proper comparisons can be undertaken and the staging of the Games improved through a better matching of Games-related revenues and expenditures. The author presents a summary of the surpluses and deficits (both including and excluding the capital cost of investments) generated by the Olympics over 1972-2008, using 2003 estimates for Athens (2004) and 2001 estimates for Beijing (2008). Focusing on deficit and surplus outcomes, Montreal (1976), Munich (1972) and Sydney (2000) would be viewed as disasters by virtue of generating the largest deficits, and Los Angeles (1984) and Seoul (1988) as the greatest successes.

But success or failure needs to be interpreted much more broadly than from just the financial point of view suggested by some of the key calculations in the book. Despite the large deficit when investments are included in the calculation, the Sydney Olympics were considered the 'best games ever', presumably because of intangible subjective perceptions: for example, many respondents to postGames surveys described them as 'friendly' and 'fun'. One danger of giving top priority to generating a surplus (as could be implied from the book) is that this does not take into account the risk to sustainability of the Olympics resulting from excessive commercialisation, as was the perception following the Atlanta Games.

Generally, this chapter is disappointing. Threats to the Olympics, such as the IOC's monopolistic behaviour causing cities not to bid for the 1984 Games except with a change of hosting arrangements, and causing sports consumers to shift their spending to other expanding international sporting events, are not covered in any detail. The IOC's decision to limit the growth of the Games to avoid overcommercialisation has been mentioned, but there are a number of missing stories on aspects that challenge the perceived ideals and appeal of the Olympics (for example, the impact of corruption in the bidding process, the use of performance enhancing drugs, etc.). Another threat is terrorism, which raised its head at the Munich Olympics in 1972, and now imposes a large additional cost. The opportunity costs for top athletes to compete at the Olympics are also a threat.

Overall, this book fails fully to satisfy in relation to the wide range of interests it attempts to address. This is partly the result of becoming bogged down in accounting detail and the author's use of a large number of complex charts. It is also rather difficult to read, and the indexing could have been improved.

\section{Reference}

Simson, V. and A. Jennings (1992), The Lords of the Rings - Power, Money and Drugs in the Modern Olympics, Simon \& Schuster, London.

Ray Trewin is Visiting Fellow, Asia Pacific School of Economics and Government, the Australian National University. 